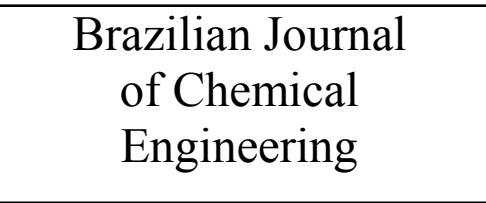

ISSN 0104-6632

Printed in Brazil www.abeq.org.br/bjche

Vol. 24, No. 02, pp. 211 - 221, April - June, 2007

\title{
A NEW SIMULATION METHOD FOR THE SEPARATION OF BINARY MIXTURES IN A FOUR-COLUMN SIMULATED MOVING BED
}

\author{
A. N. V. R. D. Starquit, R. Guirardello, and M. A. Cremasco* \\ School of Chemical Engineering, State University of Campinas, \\ PO Box 6066, 13083-970, Campinas - SP, Brazil \\ E-mail: cremasco@feq.unicamp.br \\ (Received: September 15, 2003 ; Accepted: January 25, 2007)
}

\begin{abstract}
In this paper, a new resolution method for the dynamic simulation of a simulated moving bed is presented. A general rate model for each solute and each column is presented for the case of a linear isotherm. A hybrid resolution is developed, in which an analytical solution is used for the solid stationary phase, while the mobile fluid phase concentrations are obtained by numerical resolution. It is illustrated, through a numerical study, that the resolution method is robust. The method is validated by comparison with previously published experimental results. It is also shown that these numerical simulations are obtained much faster than those based on the physical separation process, allowing the use of this resolution method for on-line applications and process control.

Keywords: Simulated moving bed; Chromatography; Dynamic simulation; General rate model.
\end{abstract}

\section{INTRODUCTION}

The simulated moving bed (SMB) technique has been used in the petrochemical industries for some decades (Broughton, 1968). It has also been applied in the food industry (Ching et al., 1991; Mallmann et al., 1998). However, for the separation of fine chemicals and biochemical products on an industrial scale, batch chromatography is commonly used. But the simulated countercurrent adsorber has attracted much attention ( $\mathrm{Lu}$ and Ching, 1997; Pais et al., 1997; Wu et al., 1998; Santos et al., 2004) because it permits a decrease in solvent consumption and an increase in the products purity and yield over preparative elution chromatography (Wu et al., 1998).

Due to the complexity of the SMB process, simulations are necessary at many stages in the development of a specific application. To perform such simulations, several models from the literature (Ching et al., 1994; Pais et al., 1997) can be used.

There are two mainly approaches to the modeling of an SMB. In the first one (Ching et al., 1991; Lu and Ching, 1997; Lehoucq et al., 2000), the SMB is represented by an equivalent true moving bed (TMB). This approach results in a set of ordinary differentials equations, a mathematical problem for which many resolution methods can be used. With this kind of modeling, the time average behavior of the SMB can be determined rapidly, but information on the intrinsic dynamic behavior of the SMB is lost, limiting comprehension of the process and prreventing the application of such models for process control (Dünnebier et al., 1998).

The second approach consists of a dynamic modeling that considers separately each column

*To whom correspondence should be addressed 
and the real successive position switches in the process. When using this dynamic modeling, a chromatographic model for representing each individual column must be chosen. With the ideal plug flow model, an analytical solution was proposed (Zhong and Guiochon, 1996). Yet, it has been shown that nonidealities cannot be, in many practical applications, neglected (Zhong and Guiochon, 1997), so numerical simulations are indispensable. A fast and accurate resolution scheme, using a closed-form solution, was also proposed (Dünnebier et al., 1998).

However, when a general rate model is used to represent mass transfer in each column, almost all authors (Ching et al., 1991; Mallmann et al., 1998; Toumi et al., 2003; Yu and Ching, 2003) use the orthogonal collocation technique to solve the problem. As far as we know, there is one study (Haag et al., 2001) that uses an alternative resolution strategy with this model, applying the finite differences method for the discretization of the spatial side of the equations and a STIFF integrator to calculate the time evolution. The orthogonal collocation technique has the advantage of being very accurate and very robust. However, this method is very time consuming so that it cannot generaly be used for on-line applications and process control.

The aim of this work is to develop an alternative numerical resolution strategy for the dynamic prevision of a four-column SMB process, using a general rate model for each column and each solute. The strategy developed is limited to a linear isotherm, but this is also the limitation of the analytical solution (Zhong and Guiochon, 1996) and of the fast closed-form solution (Dünnebier et al., 1998). It will be shown that the new approach developed is robust and produces reliable results more rapidly than the physical process, with a current basic computer model (PC Celeron 733Mhz). Finally, the resolution method will be validated by the comparison of simulated results with experimental ones from the literature (Cremasco et al., 2000).

\section{THE SIMULATED MOVING BED PROCESS}

An SMB is composed of a series of fixed-bed columns, connected together to form a closed loop. In the classical scheme, the loop is divided into four zones by two inlet (feed and solvent) and two outlet (raffinate and extract) ports, as shown in Figure 1. Periodically $\left(t_{\text {switch }}\right)$, the position of the different inlets and outlets streams are moved by one column in the solvent flow direction. This switching causes an apparent countercurrent movement of the solid, which permits approaching a continuous countercurrent system by the use of a dynamic process (Ruthven and Ching, 1989) without the actual difficulties encountered with the real solid movement.

If the different flow rates and the switching time are correctly chosen, the low-affinity solute, A, is recovered at the raffinate port, while the high-affinity solute, $\mathrm{B}$, is recovered at the extract port. Two design methods are well described in the literature. The triangle method (Storti et al., 1993), based on the ideal model, considers only the isotherm thermodynamics, while the standing wave analysis (Ma and Wang, 1997; Cremasco and Wang, 2003a) also takes into account nonidealities such as dispersive effects and mass transfer resistances

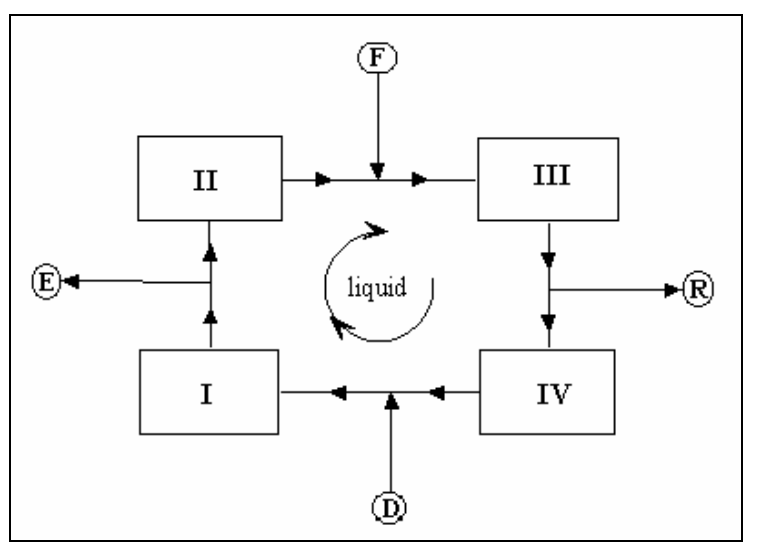

Figure 1: Four zones in an SMB system. 


\section{THEORY}

The modeling strategy chosen to represent the SMB process consists of a dynamic modeling in which each column is modeled individually by a general rate model. In order to obtain this mathematical model, some assumptions must be made. In the present work these assumptions are as follow: the flow rates are constant in each zone; the transversal cross section is constant for and through all columns; radial dispersion can be neglected; the axial dispersion coefficients $\left(E b_{j}^{i}\right)$ are a function of solute and flow rate; the external mass transfer resistance is negligible $(\mathrm{Bi} \rightarrow \infty)$; the solid is made of spherical particles of uniform radius; solutions are diluted and thus adsorption is linear; and the pore diffusion model describes the intra-particle transport mechanism.

Based on the previous hypothesis, the adsorption process for each solute in each column can be described by the following set of equations:

\section{Solid Phase}

$$
\begin{aligned}
& \varepsilon_{\mathrm{p}} \frac{\partial \mathrm{Cp}_{\mathrm{j}}^{\mathrm{i}}}{\partial \mathrm{t}}+\left(1-\varepsilon_{\mathrm{p}}\right) \frac{\partial \mathrm{q}_{\mathrm{j}}^{\mathrm{i}}}{\partial \mathrm{t}}= \\
& =\varepsilon_{\mathrm{p}} \mathrm{D}_{\mathrm{P}}^{\mathrm{i}} \frac{1}{\mathrm{r}^{2}} \frac{\partial}{\partial \mathrm{r}}\left(\mathrm{r}^{2} \frac{\partial \mathrm{C} \mathrm{p}_{\mathrm{j}}^{\mathrm{i}}}{\partial \mathrm{r}}\right) \\
& \mathrm{q}_{\mathrm{j}}^{\mathrm{i}}=\mathrm{k}_{\mathrm{p}}^{\mathrm{i}} \mathrm{C} \mathrm{p}_{\mathrm{j}}^{\mathrm{i}}
\end{aligned}
$$

where $\mathrm{Cp}$ is the solute concentration in the liquid phase inside the particle pores (volume fraction $\varepsilon_{\mathrm{p}}$ ), $\mathrm{q}$ is the solute concentration on the solid surface (volume fraction $1-\varepsilon_{\mathrm{p}}$ ), and indices, $\mathrm{i}$ and $\mathrm{j}$, refer to solute and column, respectively.

\section{Fluid Phase}

$$
\frac{\partial C_{j}^{i}}{\partial t}=E b_{j}^{i} \frac{\partial^{2} C_{j}^{i}}{\partial z^{2}}-u_{j} \frac{\partial C_{j}^{i}}{\partial z}-\frac{1-\varepsilon}{\varepsilon} R^{i}{ }_{j}^{i}
$$

where $\mathrm{C}$ is the solute concentration in the fluid phase (volume fraction $\varepsilon$ ) and $\mathrm{Ra}$, the rate of adsorption/desorption of solute by the solid, by reactor volume unit, which is expressed as

$$
\mathrm{Ra}_{\mathrm{j}}^{\mathrm{i}}=\frac{3}{\mathrm{R}^{3}} \frac{\partial}{\partial \mathrm{t}}\left\{\int_{0}^{\mathrm{R}}\left[\varepsilon_{\mathrm{p}} \mathrm{Cp} \mathrm{p}_{\mathrm{j}}^{\mathrm{i}}+\left(1-\varepsilon_{\mathrm{p}}\right) \mathrm{q}_{\mathrm{j}}^{\mathrm{i}}\right] \mathrm{r}^{2} \mathrm{dr}\right\}
$$

Using equation (2) in (1) and (4), one can obtain

$$
\begin{aligned}
& {\left[\varepsilon_{\mathrm{p}}+\left(1-\varepsilon_{\mathrm{p}}\right) \mathrm{k}_{\mathrm{p}}^{\mathrm{i}}\right] \frac{\partial \mathrm{C} \mathrm{p}_{\mathrm{j}}^{\mathrm{i}}}{\partial \mathrm{t}}=} \\
& =\varepsilon_{\mathrm{p}} \mathrm{D}_{\mathrm{P}}^{\mathrm{i}}\left(\frac{2}{\mathrm{r}} \frac{\partial \mathrm{C} \mathrm{p}_{\mathrm{j}}^{\mathrm{i}}}{\partial \mathrm{r}}+\frac{\partial^{2} \mathrm{C} \mathrm{p}_{\mathrm{j}}^{\mathrm{i}}}{\partial \mathrm{r}^{2}}\right) \\
& \mathrm{Ra}_{\mathrm{j}}^{\mathrm{i}}=\frac{3}{\mathrm{R}^{3}}\left[\varepsilon_{\mathrm{p}}+\left(1-\varepsilon_{\mathrm{p}}\right) \mathrm{k}_{\mathrm{p}}^{\mathrm{i}}\right] \frac{\partial}{\partial \mathrm{t}}\left\{\int_{0}^{\mathrm{R}} \mathrm{Cp}_{\mathrm{j}}^{\mathrm{i}} \mathrm{r}^{2} \mathrm{dr}\right\}
\end{aligned}
$$

The initial and boundary conditions that describe the adsorption process are expressed as follows:

$$
\begin{array}{ll}
C_{j}^{i}=q_{j}^{i}=0 & \text { for } t=0 \\
\frac{\partial C p_{j}^{i}}{\partial r}=0 & \text { for } r=0 \\
C p_{j}^{i}=C_{j}^{i} & \text { for } r=R
\end{array}
$$

Note that equation (9) can be written in this simplified form because, in this work, $\mathrm{Bi} \rightarrow \infty$ is assumed

$$
\begin{aligned}
& \frac{\partial C_{j}^{i}}{\partial z}=0 \quad \text { for } z=L_{C} \\
& \frac{\partial C_{j}^{i}}{\partial z}=\frac{u_{j}}{E b_{j}^{i}}\left(C_{j}^{i}-C o_{j}^{i}\right) \quad \text { for } z=0
\end{aligned}
$$

where Co is the solute concentration in the column inlet flow, which depends on the system evolution as shown in equations (12).

$$
\mathrm{Co}_{\mathrm{III}}^{\mathrm{i}}=\frac{\left.\mathrm{Q}_{\mathrm{II}} \cdot \mathrm{C}_{\mathrm{II}}^{\mathrm{i}}\right|_{\mathrm{z}=\mathrm{L}_{\mathrm{II}}}+\mathrm{Q}_{\mathrm{F}} \cdot \mathrm{C}_{\mathrm{F}}^{\mathrm{i}}}{\mathrm{Q}_{\mathrm{III}}}
$$

For the column next to the feed port

$$
\mathrm{Co}_{\mathrm{I}}^{\mathrm{i}}=\left.\frac{\mathrm{Q}_{\mathrm{IV}}}{\mathrm{Q}_{\mathrm{I}}} \cdot \mathrm{C}_{\mathrm{IV}}^{\mathrm{i}}\right|_{\mathrm{z}=\mathrm{L}_{\mathrm{IV}}}
$$

For the column next to the solvent port

$$
\mathrm{Co}_{\mathrm{j}}^{\mathrm{i}}=\left.\mathrm{C}_{\mathrm{j}-1}^{\mathrm{i}}\right|_{\mathrm{z}=\mathrm{L}_{\mathrm{C}}}
$$

For the other columns 
Most of the parameters necessary for the simulations were estimated using correlations from the literature. The axial dispersion coefficient can be calculated from (Athayle et al., 1992):

$$
\frac{\mathrm{Eb}}{\mathrm{uR}}=2\left(\frac{\mathrm{Pe}_{\mathrm{MP}}}{1-\varepsilon}\right)^{1 / 6}
$$

with the molecular mass Peclet number for a particle defined by

$$
\mathrm{Pe}_{\mathrm{Mp}}=\frac{2 \mathrm{uR} \varepsilon_{\mathrm{p}}}{\mathrm{D}_{\mathrm{AB}}}
$$

The effective diffusion coefficient is obtained by (Mackie and Meares, 1955):

$$
\mathrm{D}_{\mathrm{P}}=\frac{\varepsilon_{\mathrm{p}}}{\left(2-\varepsilon_{\mathrm{p}}\right)^{2}} \mathrm{D}_{\mathrm{AB}}
$$

\section{NUMERICAL RESOLUTION}

The resolution method used in this work is a hybrid method based on previous work (Cremasco et al., 2003b) in which was developed for prediction of breakthrough curves for the adsorption of a singlee. The intra-particle liquid solute concentration is found analytically and correlated to the liquid bed concentration through Duhamel's theorem. Nonetheless, bed concentration must be determined numerically due to the not a priori unown time evolution of boundary conditions expressed by equations (12).

The use of Duhamel's theorem results in an equation connecting the intraparticle liquid concentration, $\mathrm{Cp}$, to the liquid bed concentration, $\mathrm{C}$. This correlation is expressed as

$$
C p_{j}^{i}=\int_{0}^{t}\left[-\frac{\partial \theta^{i}(r, t-\tau)}{\partial \tau}\right] C_{j}^{i} d \tau
$$

were $\theta$ is the dimensionless solution $\left(C_{j}^{i}=1\right)$ of the problem established by equation (5), initial condition (7), and boundary conditions (8) and (9). However, in order to express $\mathrm{Ra}$, it is more convenient to use the average dimensionless concentration, $\bar{\theta}$, efined as

$$
\bar{\theta}^{\mathrm{i}}(\mathrm{t})=\frac{3}{\mathrm{R}^{3}} \int_{0}^{\mathrm{R}} \theta^{\mathrm{i}}(\mathrm{r}, \mathrm{t}) \mathrm{r}^{2} \mathrm{dr}
$$

Substituting the analyticalolution into the previous equation results in (Crank, 1957):

$$
\bar{\theta}^{\mathrm{i}}=1-\frac{6}{\pi^{2}} \sum_{\mathrm{n}=1}^{\infty} \frac{1}{\mathrm{n}^{2}} \exp \left(-\mathrm{n}^{2} \cdot \pi^{2} \mathrm{Fo}_{M}{ }^{\mathrm{i}}\right)
$$

were the modified Fourier-mass number is

$$
\mathrm{Fo}_{\mathrm{M}}^{\mathrm{i}}=\frac{\varepsilon_{\mathrm{p}}}{\left[\varepsilon_{\mathrm{p}}+\left(1-\varepsilon_{\mathrm{p}}\right) \mathrm{k}_{\mathrm{p}}^{\mathrm{i}}\right]} \frac{\mathrm{D}_{\mathrm{p}}^{\mathrm{i}} \mathrm{t}}{\mathrm{R}^{2}}
$$

Using the average concentration, $\bar{\theta}$, and Duhamel's theorem, equation (6) can be rearranged to obtain

$$
\begin{aligned}
& \operatorname{Ra}_{j}^{i}=\left[\varepsilon_{p}+\left(1-\varepsilon_{p}\right) k_{p}^{i}\right] \\
& \frac{\partial}{\partial t}\left\{\left.\int_{0}^{t} \frac{d \bar{\theta}^{i}(\xi)}{d \xi}\right|_{\xi=t-\tau} C_{j}^{i}(z, \tau) \cdot d \tau\right\}
\end{aligned}
$$

This expression is introduced into equations (3), which are numerically solved by a first-order discretization method. As a result, some linear tridiagonal sets of equations have to be solved, which is accomplished using the Thomas algorithm.

In the case of an SMB, all algebraic sets of equations have to be solved simultaneously in order to be able to calculate the column entrance concentration in the next time step using of equations (12). To do so, it is easier to work with a fixed time integration step, $\Delta \mathrm{t}$, and a calculated spatial step, $\Delta \mathrm{z}_{\mathrm{j}}^{\mathrm{i}}$, contrary what was done in previous work (Cremasco et al., 2003b) for a one-specie breakthrough curve prediction.

Also, in the physical process, one can assume that the past concentration in the column will not influence the rate of adsorption at the present time. Mathematically, the derivative in equation (20) rapidly tends to zero when $\tau$ tends to zero. For this reason, the integral in equation (20) is estimated during a time interval starting only at the beginning of the past switching period and ending at the time at which the concentrations are being calculated. This allows us to reduce both the computing time and the memory use. 


\section{RESULTS AND DISCUSSION}

\section{Numerical Study}

Numerical results are obtained for the separation of two amino acids, phenylalanine (Phe) and tyrosine (Tyr). All simulations were carried out on a PC equipped with a 733Mhz Intel Celeron processor and with $240 \mathrm{Mb}$ of Ram memory. The values of the solute properties $\left(\mathrm{D}_{\mathrm{AB}}\right.$ and $\mathrm{k}_{\mathrm{p}}$ ) were found in the literature (Cremasco et al., 2001). Based on those values, the effective pore diffusion coefficients, $D_{p}$, and the axial dispersion coefficient, $\mathrm{Eb}$, can be obtained using of equations (13) through (15).

In all presently studied cases, a four-column SMB with one column in each zone is simulated. The physical parameters are presented in Table 1, while the different operating conditions explored are summarized in Table 2, both from previous experimental work (Cremasco et al., 2000) in which they were determined by the standing wave theory. In order to simplify the notation, the solute with less affinity for the solid (Phe) will be referred to as A and the one with stronger affinity (Tyr), as B.

It can be clearly seen in Figure 2 that the SMB technique is a dynamic process, since the various exit concentrations are in continuous evolution. But one also perceives that after 11 switching periods, the raffinate port results have almost attained the cyclic steady state at which the varying pattern repeats itself after each swap.

For easier interpretation and further comparison with experimental results, an average curve is calculated for all exit streams, as shown in Figure 2. This calculation is computed using the trapezoidal rule for each switching period, and the result is assumed to be attained at the middle of the given period.

A study was made to determine the grid refinement required to achieve good precision, without spending unnecessary computing time. The discretization parameter utilized for this study, M, represents the of time intervals into which the switching period is divided.

Table 1: Column and adsorvent properties (Cremasco et al., 2000).

\begin{tabular}{|c|c|c|c|c|}
\hline $\begin{array}{c}\mathbf{L}_{\mathbf{C}} \\
(\mathbf{c m})\end{array}$ & $\begin{array}{c}\mathbf{D} \\
(\mathbf{c m})\end{array}$ & $\boldsymbol{\varepsilon}$ & $\begin{array}{c}\mathbf{R} \\
(\boldsymbol{\mu m})\end{array}$ & $\boldsymbol{\varepsilon}_{\mathbf{p}}$ \\
\hline 12.5 & 1.5 & 0.37 & 180 & 0.55 \\
\hline
\end{tabular}

Table 2: Operating conditions for the runs (Cremasco et al., 2000).

\begin{tabular}{|c|c|c|c|c|c|c|c|}
\hline Run & $\begin{array}{c}\mathrm{C}_{\mathrm{F}}^{\mathrm{A}} \\
(\mathbf{g} / \mathbf{L})\end{array}$ & $\begin{array}{c}\mathrm{C}_{\mathrm{F}}^{\mathrm{B}} \\
\mathbf{( g / \mathbf { L } )}\end{array}$ & $\begin{array}{c}\mathbf{t}_{\text {switch }} \\
\mathbf{( m i n )}\end{array}$ & $\begin{array}{c}\mathbf{Q}_{\text {I }} \\
(\mathbf{m l} / \mathbf{m i n})\end{array}$ & $\begin{array}{c}\mathbf{Q}_{\text {II }} \\
(\mathbf{m l} / \mathbf{m i n})\end{array}$ & $\begin{array}{c}\mathbf{Q}_{\text {III }} \\
(\mathbf{m l} / \mathbf{m i n})\end{array}$ & $\begin{array}{c}\mathbf{Q}_{\text {IV }} \\
(\mathbf{m l} / \mathbf{m i n})\end{array}$ \\
\hline 1 & 0.882 & 0.163 & 17.9 & 2.14 & 1.81 & 2.07 & 1.31 \\
\hline 2 & 0.994 & 0.194 & 53.3 & 0.79 & 0.59 & 0.65 & 0.48 \\
\hline
\end{tabular}

Simulations for Run 1 are obtained for $\mathrm{M}=300$, $400,500,550,600,700,800,900$, and 1000. With the aim of simplicity, Figure 3 presents only some of the results for solute $\mathrm{B}$ at the extract port, which appear to be the results requiring the finest discretization grid.

As can be seen in Figure 3, the results for all discretizations are in close agreement. Still, there is a $2 \%$ difference between the results obtained with the smallest $\mathrm{M}$ parameter value and those obtained with the highest one. As the discretization grid is refined, numerical results closer to the ones with $M=1000$, and for $M=600$ or higher values there are no more significant variations. On the other hand, computing time increases a lot with grid refinement, as can be seen in Table 3 where compared the computing time necessary to obtain the simulated curves are given in Figure 3. So, if a very fast response is the objective, an acceptable simulation can be performed with a not so refined grid, while when high precision is required, a more refined grid can be used, and still the simulation is faster than the physical process with a current basic computer model (PC with PIII Celeron 733Mhz).

A similar numerical study is done for Run 2, using $M=200,300,400,500$, and 600 . In this case, as can be observed in Figure 4, results with $M=300$ do not differ significantly from the ones with the higher $M$ value, suggesting that when zone flow rates decrease, the grid can be less refined. Yet, for further investigations, a constant $\mathrm{M}$ value of 600 will be used in the present study. 


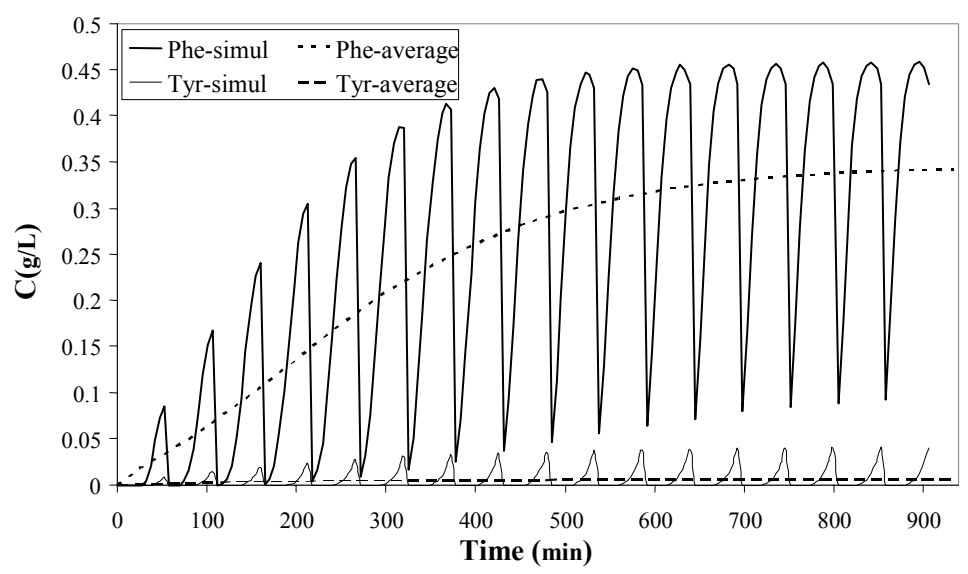

(a)

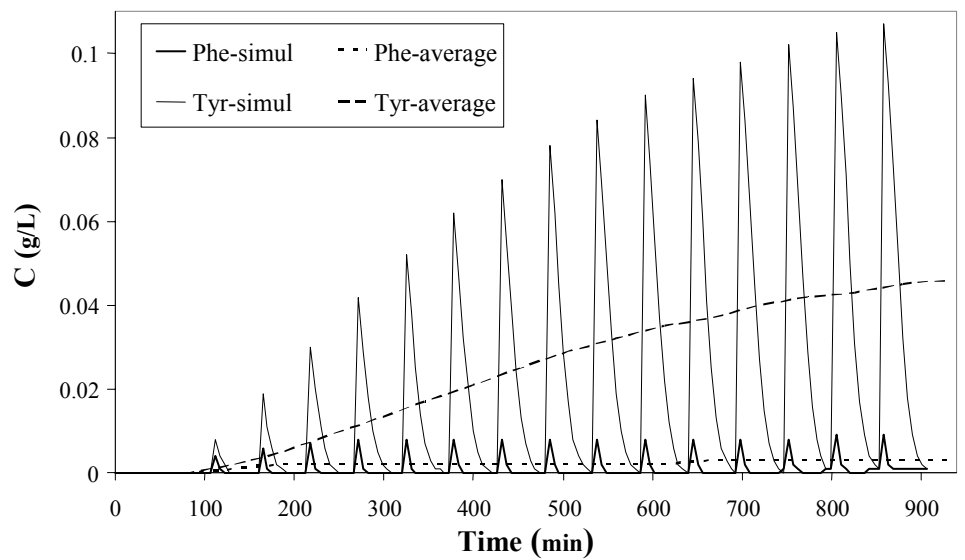

(b)

Figure 2: Simulated outlet concentrations for Run 2: (a) Raffinate port; (b) Extract port.

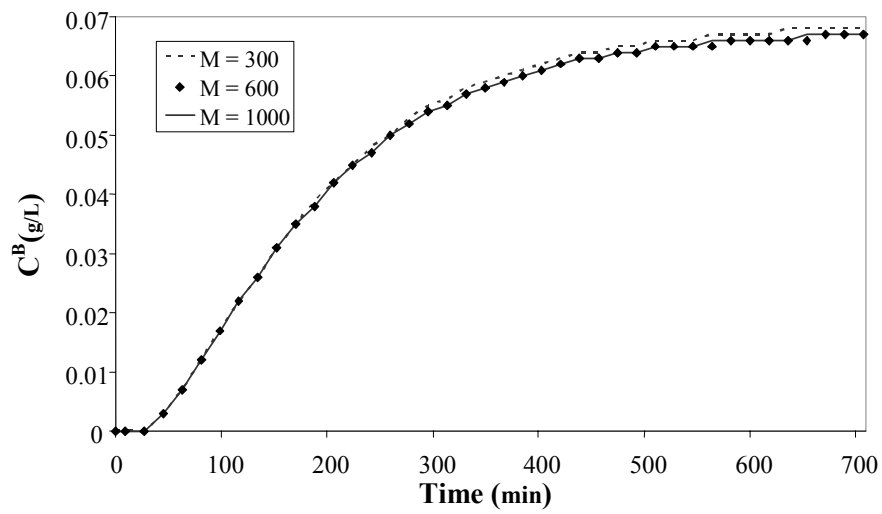

Figure 3: Influence of temporal discretization on simulated extract concentration (Run 1).

Table 3: Computing time as a function of temporal discretization.

\begin{tabular}{|c|c|c|c|}
\hline M & $\mathbf{3 0 0}$ & $\mathbf{6 0 0}$ & $\mathbf{1 0 0 0}$ \\
\hline Calculation time $(\mathrm{min})$ & 17 & 134 & 706 \\
\hline
\end{tabular}




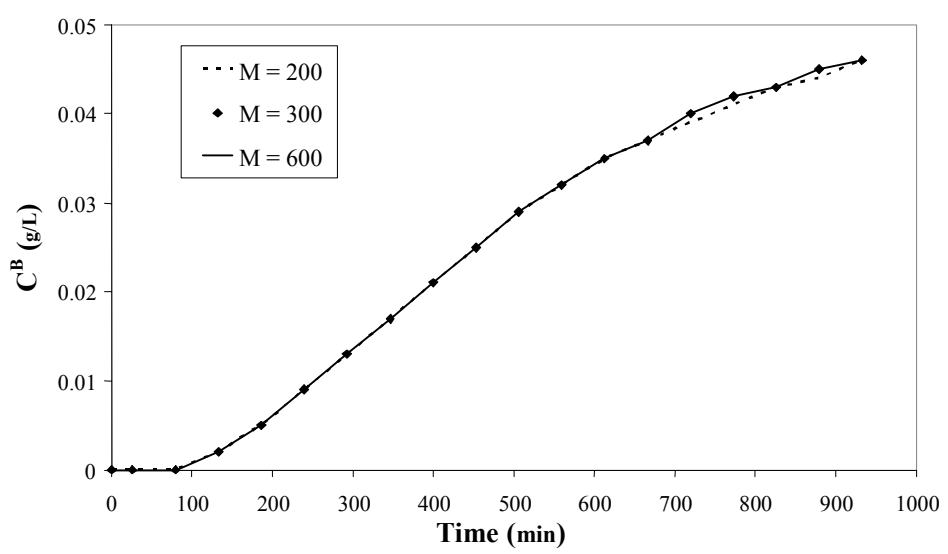

Figure 4: Influence of temporal discretization on simulated extract concentration (Run 2).

\section{Comparison with Experimental Results}

In order to validate the resolution method, the simulated curves are compared with experimental results from the literature (Cremasco et al., 2000). These comparisons are presented in Figures 5 and 6 for Runs 1 and 2, respectively. The simulated curves satisfactorily predict all effluent profiles, assuming that the physical parameters were not adjusted, that the comparisons are based on average values over each switching periods, and that the error on the experimental values are unknown.

Note also that a slight error in the zone flow rates inherent in pump precision $(0.1 \mathrm{ml} / \mathrm{min})$ could considerably influence the outlet stream concentrations, as shown in previous work (Cremasco et al., 2000). As pump precision is independent of zone flow rates, experiments with lower flow rates would be affected much more significantly by this experimental imprecision.

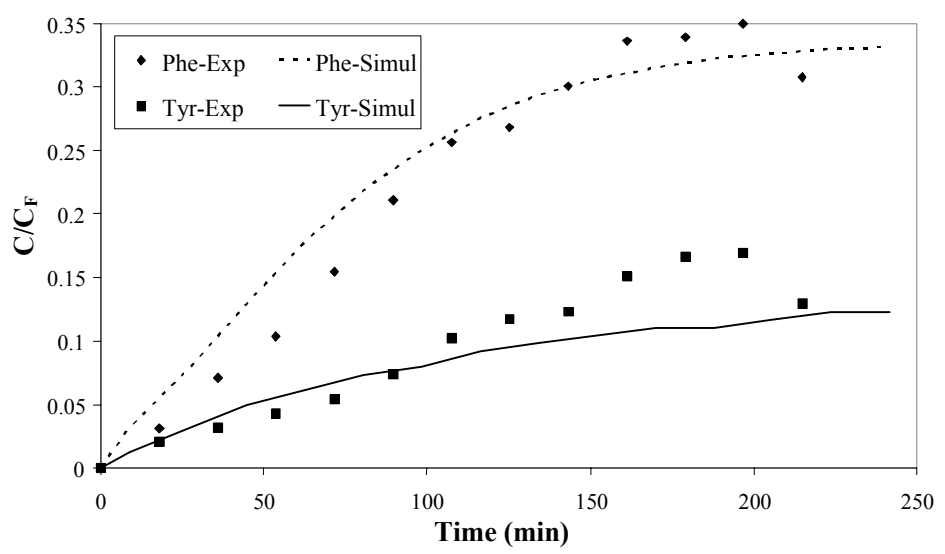

(a)

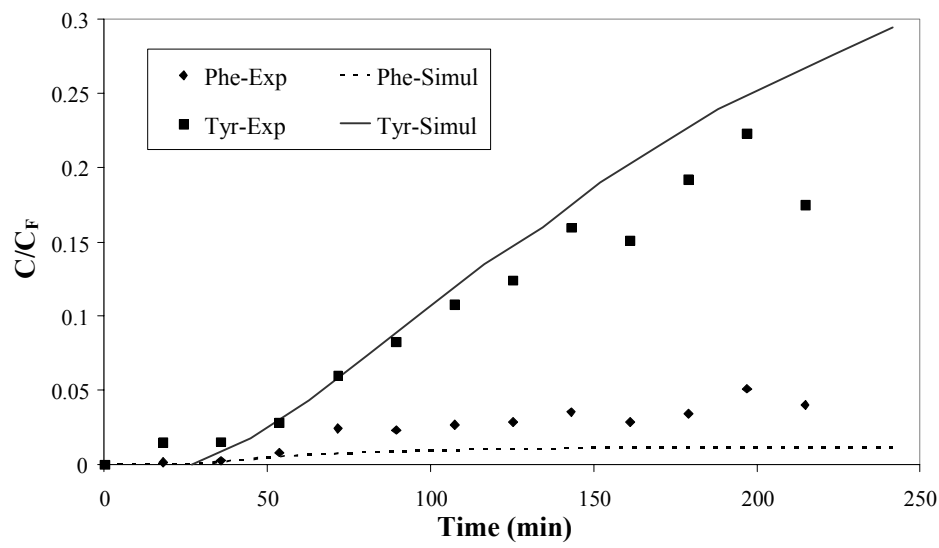

(b)

Figure 5: Comparison between simulated and experimental results for Run 1: (a) Raffinate port; (b) Extract port. 


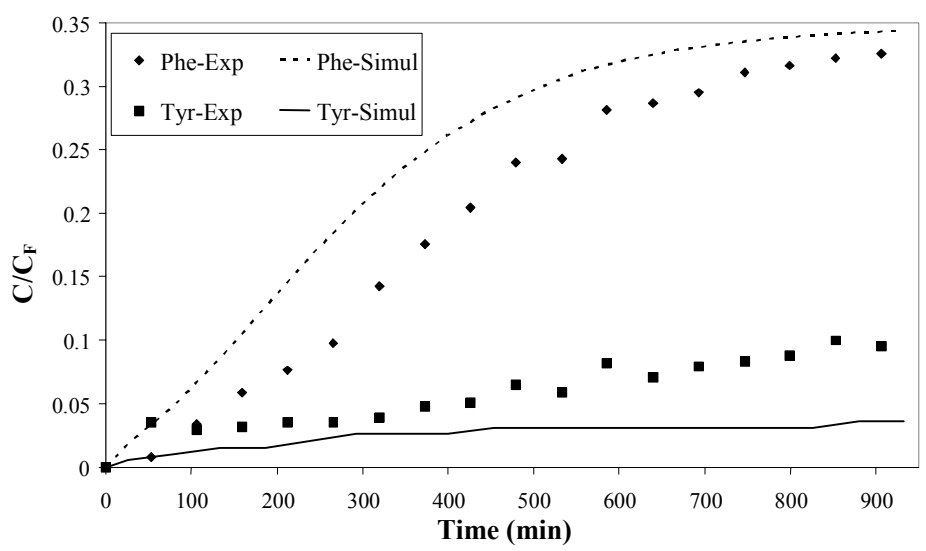

(a)

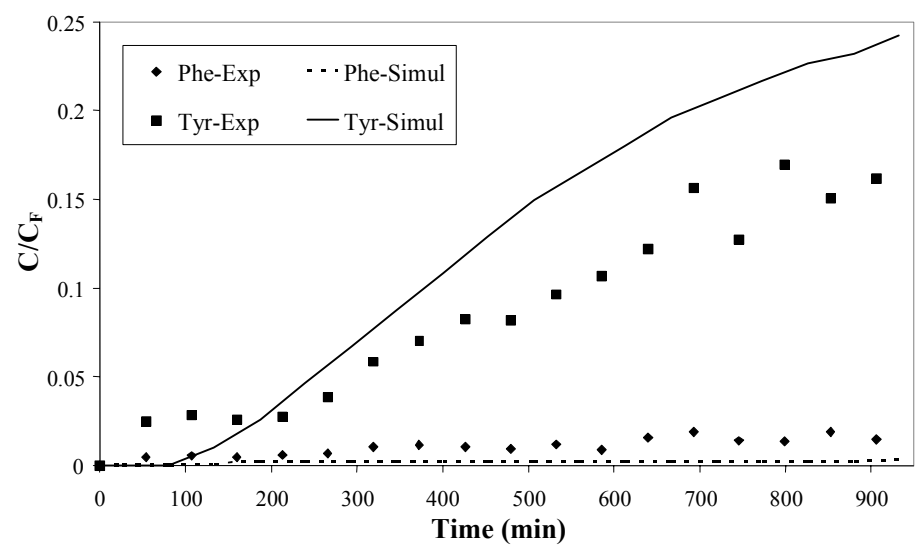

(b)

Figure 6: Comparison between simulated and experimental results for Run 2:

(a) Raffinate port; (b) Extract port.

\section{Internal Concentration Profiles}

To complete the study, the time evolution of the axial profiles, at steady state, is shown in Figures 7 and 8. This information cannot be obtained through the experiments or by the use of a TMB model and is very important to understanding the intrinsic dynamic behavior of the SMB process. Figures 7 and 8 contain the profiles at the beginning, middle, and end of the $40^{\text {th }}$ switching period for Runs 1 and 2, respectively.

The solutes waves can be clearly observed in Figures 7 and 8 . At the raffinate port, the solute concentration with less affinity increases during the switching period. At the end of the interval, the concentration of solute with more affinity increases quickly and contamination begins. To obtain good purities, the columns switched are operated which maintains the waves in their respective zones, since the profiles will be the same as at the beginning of the previous period.

One could try to increase the purity of the solute with less affinity by shortening the switching period, however, this would increase the extract impurities and probably diminish the yield of solute recuperated at the raffinate port. Therefore, it is better to make use of a rigorous procedure, such as the standing wave analysis method (Ma and Wang, 1997; Cremasco and Wang, 2003a) in order to determine the operating conditions of a simulated countercurrent contactor bed. 


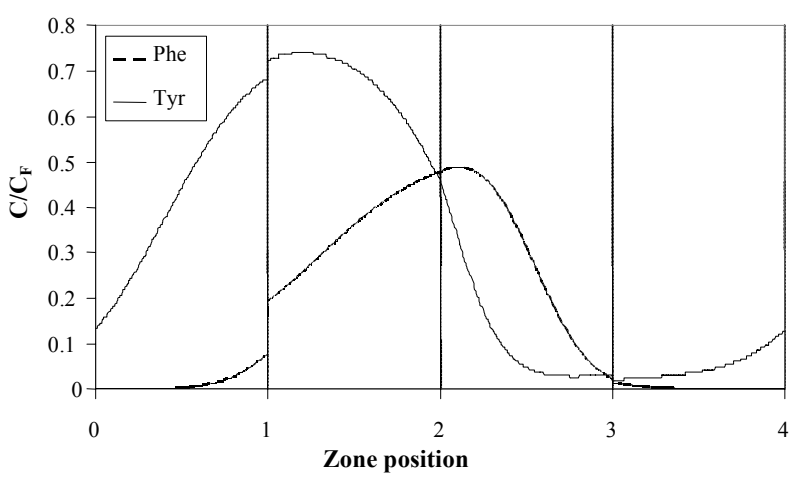

(a)

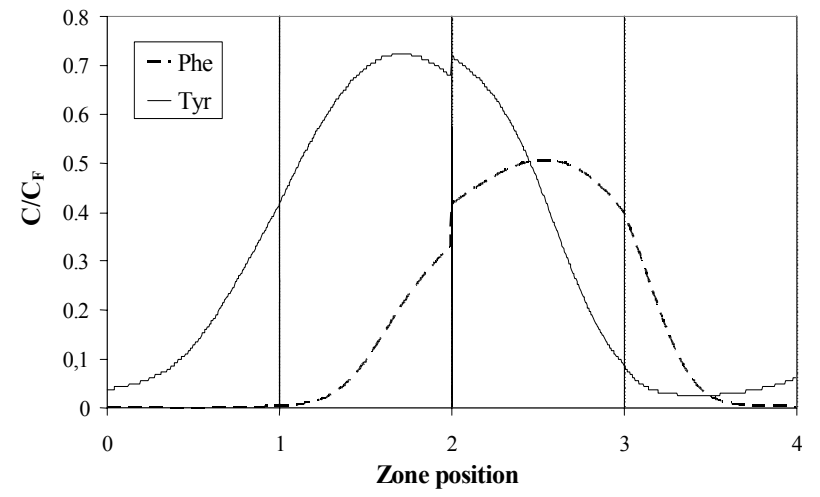

(b)

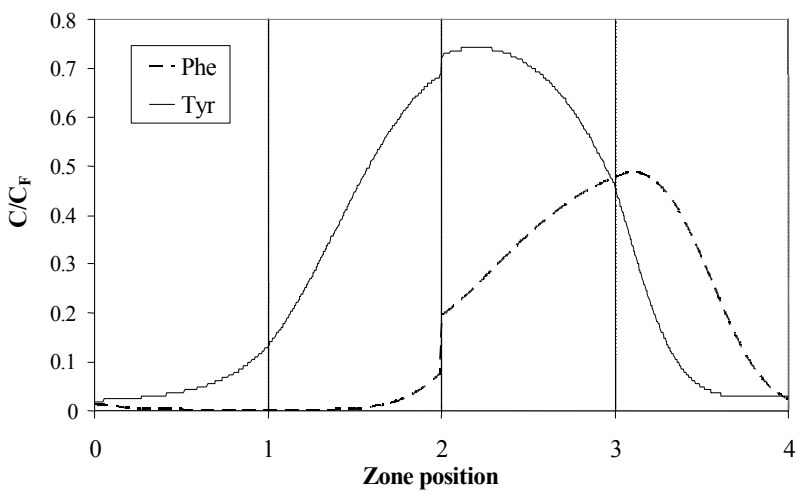

(c)

Figure 7: Time evolution of the axial profiles at steady state for Run 1:

(a) $t=519.1 \mathrm{~min}$; (b) $t=528.05 \mathrm{~min}$; (c) $t=537 \mathrm{~min}$.

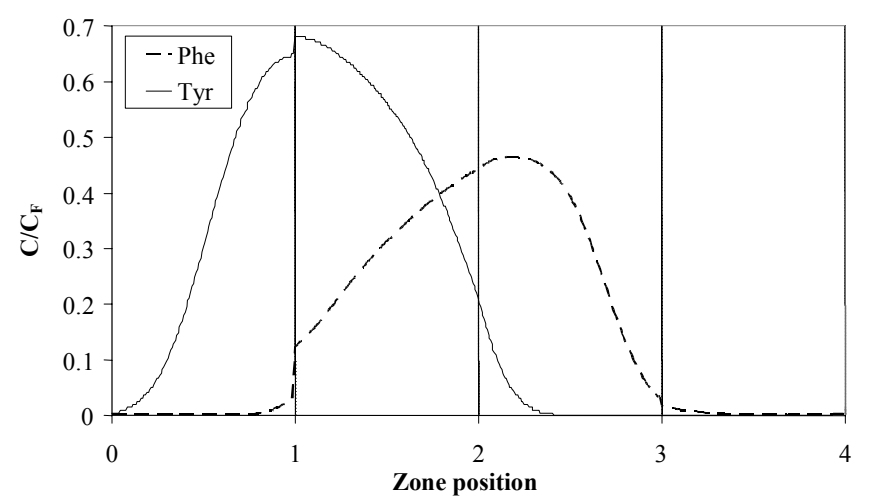

(a)

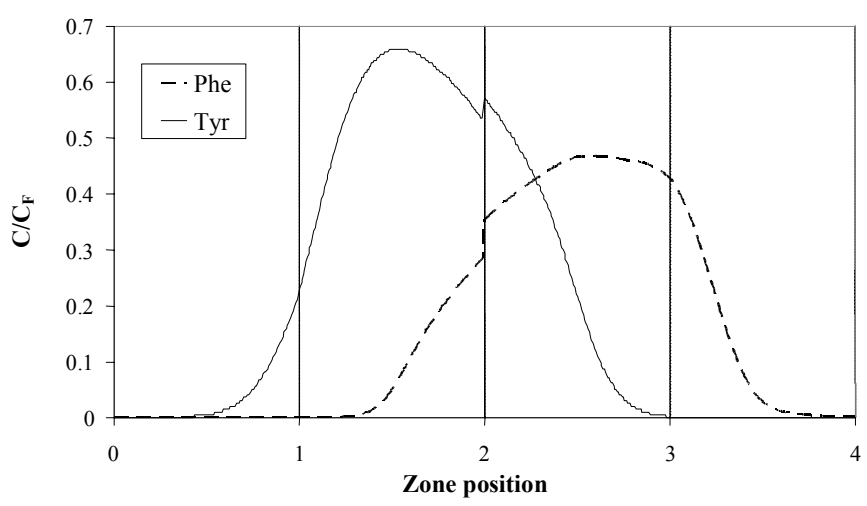

(b)

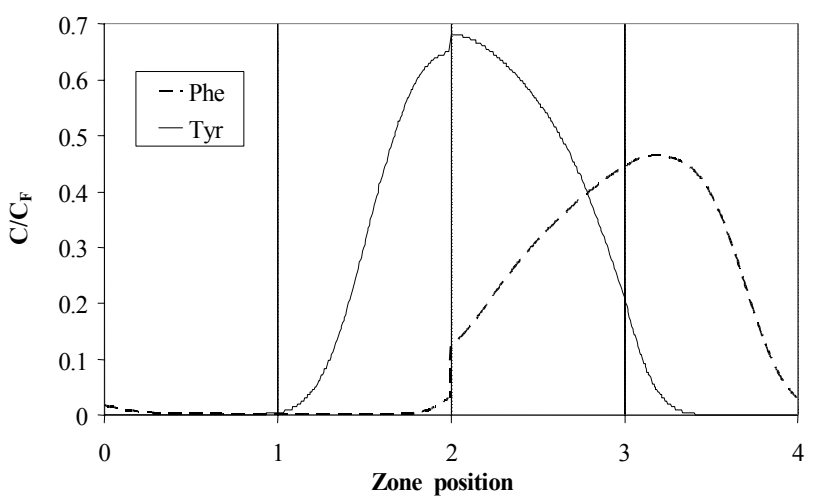

(c)

Figure 8: Time evolution of the axial profiles at steady state for Run 2:

(a) $\mathrm{t}=1545.7 \mathrm{~min}$; (b) $\mathrm{t}=1572.35 \mathrm{~min} ;$ (c) $\mathrm{t}=1599 \mathrm{~min}$ 


\section{CONCLUSIONS}

A new resolution strategy for prediction of SMB behavior using a general rate model was presented in this paper. A numerical study was performed and attested that the new resolution method is very robust and numerically stable. It was shown that the approach developed produces reliable predictive results in a shorter time than the physical separation process with a current basic computer model (PC Celeron $733 \mathrm{Mhz}$ ), allowing for the application of this resolution strategy for on-line uses and process control.

The model utilized in this work is limited to linear isotherm cases with negligible external resistance. Nonetheless, these simplifications are commonly used whenever they are suitable.

\section{NOMENCLATURE}

\begin{tabular}{|c|c|c|}
\hline $\mathrm{C}$ & $\begin{array}{l}\text { solute concentration in the } \\
\text { mobile phase; }\end{array}$ & $\mathrm{ML}^{-3}$ \\
\hline $\mathrm{Cp}$ & $\begin{array}{l}\text { intraparticle liquid phase } \\
\text { concentration; }\end{array}$ & $\mathrm{ML}^{-3}$ \\
\hline Co & $\begin{array}{l}\text { column injection } \\
\text { concentration; }\end{array}$ & $\mathrm{ML}^{-3}$ \\
\hline D & $\begin{array}{l}\text { column diameter; solvent } \\
\text { flow rate; }\end{array}$ & $\mathrm{L}$ \\
\hline $\mathrm{D}_{\mathrm{AB}}$ & free diffusion coefficient; & $\mathrm{L}^{2} \mathrm{~T}^{-1}$ \\
\hline $\mathrm{D}_{\mathrm{p}}$ & $\begin{array}{l}\text { effective diffusion } \\
\text { coefficient; }\end{array}$ & $\mathrm{L}^{2} \mathrm{~T}^{-1}$ \\
\hline $\mathrm{E}_{\mathrm{b}}$ & axial dispersion coefficient; & $\mathrm{L}^{2} \mathrm{~T}^{-1}$ \\
\hline $\mathrm{k}_{\mathrm{p}}$ & $\begin{array}{l}\text { equilibrium partition } \\
\text { constant; }\end{array}$ & $(-)$ \\
\hline $\mathrm{L}_{\mathrm{c}}$ & single column length; & $\mathrm{L}$ \\
\hline $\mathrm{q}$ & $\begin{array}{l}\text { superficial solid intraparticle } \\
\text { concentration; }\end{array}$ & $\mathrm{ML}^{-3}$ \\
\hline $\mathrm{R}$ & average particle radius; & $\mathrm{L}$ \\
\hline $\mathrm{t}_{\text {switch }}$ & switching period; & $\mathrm{T}$ \\
\hline 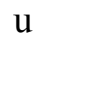 & $\begin{array}{l}\text { SMB liquid superficial } \\
\text { velocity; }\end{array}$ & $\mathrm{LT}^{-1}$ \\
\hline
\end{tabular}

\section{Greek Letters}

$\varepsilon \quad$ bed porosity;

$\varepsilon_{\mathrm{p}} \quad$ particle porosity;

$\theta \quad$ dimensionless concentration;

\section{Subscripts}

D solvent;

$\begin{array}{ll}\text { E } & \text { extract; } \\ \text { F } & \text { feed; } \\ \text { I } & \text { specie i; } \\ \text { j } & \text { zone j; } \\ \text { R } & \text { raffinate; } \\ \text { I } & \text { zone I; } \\ \text { II } & \text { zone II; } \\ \text { III } & \text { zone III; } \\ \text { IV } & \text { zone IV; }\end{array}$

\section{REFERENCES}

Athalye, A.M., Gibbs, S.J., and Lightfoot, E.N. (1992), Predictability of Chromatographic Protein Separations: Study of Size-exclusion Media with Narrow Particle Size Distribution. J. Chrom., vol. 589, pp 71-85.

Broughton, D.B. (1968), Molex: Case History of a Process. Chem. Eng. Prog, vol. 64, pp. 60-65.

Ching, C.B., Chu, K.H., Hidajat, K., and Uddin, M.S. (1991), Experimental and Modeling Studies on the Transient Behavior of a Simulated Countercurrent Adsorber. J. Chem. Eng. Japan, vol. 24, no. 5, pp. 614-621.

Ching, C.B., Chu, K.H., and Hidajet, K. (1994), Multicomponent Separation Using a Columnswitching Chromatographic Method. AIChE J., vol. 40, no. 11, pp. 1843-1849.

Crank, J. (1957), The Mathematics of Diffusion. Oxford University Press, London.

Cremasco, M.A., Hritzko, B.J., and Wang, N.-H.L. (2000), Separation of Two Amino Acids in a Four-column Simulated Moving Bed: Experimental Study. Proceedings of XIII Brazilian Chemical Engineering Meeting, CD ROM, Águas de São Pedro, Brazil.

Cremasco, M.A., Hritzko, B.J., Xie, Y., and Wang, N.-H.L. (2001), Parameters Estimation for Amino Acids Adsorption in a Fixed Bed by Moment Analysis. Braz. J. Chem. Eng., vol.18, no. 2, pp.181-194.

Cremasco, M.A., and Wang, N.-H.L. (2003a), A Design Study of the Effects of Selectivity on Binary Separation in a Four-zone Simulated Moving Bed for Systems with Linear Isotherms. Braz. J. Chem. Eng., vol. 20, no. 2, pp. 181-190.

Cremasco, M.A., Guirardello, R., and Wang, N.-H.L. (2003b), Adsorption of Aromatic Amino Acids in a Fixed Bed Column. Braz. J. Chem. Eng., vol. 20, no. 3, pp. 327-334.

Dünnebier, G., Weirich, I., and Klatt, K.-U. (1998), Computationally Efficient Dynamic Modeling and Simulation of Simulated Moving Bed 
Chromatographic Processes with Linear Isotherms. Chem. Eng. Sci., vol. 53, no. 14, pp. 2537-2546.

Haag, J., Vande Wouwer, A., Lehoucq, S., and Saucez, P. (2001), Modeling and Simulation of a SMB Chromatographic Process Designed for Enantioseparation. Control Eng. Practice, vol. 9, no. 8, pp. 921-928.

Lehoucq, S., Verheve, D., Vande Wouwer, A., and Cavoy, E. (2000), SMB Enantioseparation: Process Development, Modeling, and Operating Conditions. AIChE J., vol. 46, no. 2, pp. 247-256.

Lu, Z.P. and Ching, C.B. (1997), Dynamics of Simulated Moving-bed Adsorption Separation Processes. Separation Science and Tech., vol. 32, no. 12, pp. 1993-2010.

Ma, Z. and Wang, N.-H.L. (1997), Standing Wave Analysis of SMB Chromatography. Linear Systems; AIChE J., vol. 43, no. 10, pp. 24882507.

Mackie, J.S. and Meares, P. (1955), The Diffusion of Electrolytes in a Cation-exchange Resin Membrane. Proc. Roy. Soc. London, Seria A, vol. 232, pp. 498-509.

Mallmann, T., Burris, B.D., Ma, Z. and Wang, N.H.L. (1998), Standing Wave Design of Nonlinear SMB Systems for Fructose Separation. AIChE J., vol. 44, no. 12, pp. 2628-2646.

Pais, L.S., Loureiro, J.W., and Rodrigues, A.E. (1997), Separation of 1,1'-bi-2-naphtol Enantiomers by Continuous Chromatography in Simulated Moving Bed. Chem. Eng. Sci., vol. 52, no. 2, pp. 245-257.

Ruthven, D.M. and Ching, C.B. (1989), Countercurrent and Simulated Counter-current
Adsorption Separation Process. Chem. Eng. Sci., vol. 44, no. 5, pp. 1011-1038.

Santos, M.A.G., Veredas, V., Silva, I.J., Correia, C.R.D., Furlan, L.T., and Santana, C.C. (2004), Simulated Moving-bed Adsorption for Separation of Racemic Mixtures. Braz. J. Chem. Eng., vol. 21, no. 1, pp. 127-136.

Storti, G., Mazzotti, M., Morbidelli, M., and Carrà, S. (1993), Robust Design of Binary Countercurrent Adsorption Separation Processes. AIChE J., vol. 39, no. 3, pp. 471-492.

Toumi, A., Engell, S., Ludemann-Hombourgre, O., Nicoud, R.M., and Bailly, M. (2003), Optimization of Simulated Moving Bed and Varicol Processes. J. Chrom. A, vol. 1006, pp. 15-31.

Wu, D.-J., Xie, Y., Ma, Z., and Wang, N.-H.L. (1998), Design of Simulated Moving Bed Chromatography for Amino Acids Separations. Ind. Eng. Chem. Res., vol. 37, pp. 4023-4035.

$\mathrm{Yu}$, H.W. and Ching, C.B. (2003), Modeling, Simulation and Operation Performance of a Simulated Moving Bed for Enantioseparation of Fluoxetine on New $\beta$-Cyclodextrin Columns. Adsorption, vol. 9, no. 3, pp. 213-223.

Zhong, G. and Guiochon, G. (1996), Analytical Solution for the Linear Ideal Model of Simulated Moving Bed Chromatography; Chem. Eng. Sci., vol. 51, no. 18, pp. 4307-4319.

Zhong, G. and Guiochon, G. (1997), Simulated Moving Bed Chromatography: Effects of Axial Dispersion and Mass Transfer under Linear Conditions. Chem. Eng. Sci., vol. 52, no. 18, pp. 3117-3132. 